\title{
Modelled distributions of ten demersal elasmobranchs of the eastern English Channel in relation to the environment
}

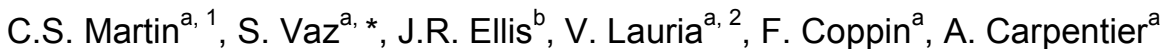

\begin{abstract}
a IFREMER, Institut français de recherche pour l'exploitation de la mer, Marine Fisheries Resource Laboratory, 150 quai Gambetta, 62321 Boulogne-sur-mer, France

b Cefas, Centre for Environment, Fisheries \& Aquaculture Science, Lowestoft Laboratory, Pakefield Road, Lowestoft, NR33 OHT, United Kingdom
\end{abstract}

${ }^{1}$ Present Address: Hellenic Centre for Marine Research (HCMR), P.O. Box 2214, 71003 Heraklion, Crete, Greece.

2 Present Address: Marine Biology and Ecology Research Centre, University of Plymouth, Drake Circus, Plymouth, Devon PL4 8AA, United Kingdom.

\author{
*: Corresponding author : Sandrine Vaz, Tel.: + 33321995632 ; fax: + 33321995601 \\ email address : svaz@ifremer.fr
}

\begin{abstract}
:
Generalised Linear Models, combined with a Geographic Information System, were used to map the habitats of ten demersal elasmobranch taxa (five skates, four sharks and a stingray) in the eastern English Channel, based on an annual fishery-independent bottom trawl survey conducted each October, and covering 21 years. Habitat models showing mean density levels were developed for the most frequently occurring species, whilst binomial occurrence habitat models were built for less frequent species. The main predictors of elasmobranch habitats in the eastern English Channel were depth, bed shear stress and salinity, followed by seabed sediment type and temperature. Habitat maps highlighted contrasting habitat utilisation across species. Raja clavata, and to a lesser extent Scyliorhinus canicula, showed ontogenetic differences in habitat utilisation, with early life history stages found in shallow coastal waters, sheltered from strong tidal currents and typically with softer sediments. Spatial segregation by sex was also evident for $S$. canicula, with females found at higher densities on some harder grounds in the study area. An improved knowledge of habitat utilisation by elasmobranchs (particularly for important life history stages and all seasons) is required if spatial management is to be considered for these species.
\end{abstract}

Highlights

GLMs and GIS were used to map the habitats of five skates, four sharks and a stingray. Predictors used included depth, sediment type, bed stress, temperature and salinity. Habitat maps highlighted contrasting habitat utilisation across elasmobranch species. - Two species showed ontogenetic differences in habitat utilisation. Spatial segregation by sex was found for one species.

Keywords: Channel Ground Fish Survey ; Chondrichthyes ; Elasmobranchii ; GLM ; Grande Ouverture Verticale ; Trawl survey

\section{Introduction}

Species distribution modelling is widely used in terrestrial and aquatic systems to predict species occurrence and to better understand the processes influencing their geographical distributions. It can also be used to assist in conservation planning and population management, and to study the effects 
of changing environmental conditions on biogeographical patterns (Guisan and Zimmermann, 2000; Thuiller et al., 2005; Guisan and Thuiller, 2005; Ramirez-Bastida et al., 2008; Vaz et al., 2008; Seo et al., 2009). Species distribution models have also been called habitat models (Elith and Leathwick, 2009) and, in the present study, habitat is seen as species-centred and environment-based, i.e. how the environment controls the spatial distribution of a species (Planque et al., 2011). This description of habitat is derived from the theoretical niche concept, in which the niche is defined as a property of the species in relation to its environment (Hutchinson, 1957).

Habitat models are commonly developed from numerical estimates of species' responses (e.g. occurrence, density) to changes in one or more environmental variables. A number of approaches have been developed to model the habitat of terrestrial and aquatic species, such as Generalized Additive Models (GAMs), neural networks, environmental envelopes and boosted decision trees (Guisan and Zimmermann, 2000; Elith et al., 2006). Generalized Linear Models (GLMs, McCullagh and Nelder, 1989), in particular, have been used successfully to predict the mean response of various species to environmental predictors. When different processes are thought to govern occurrence and density levels, a two-step approach can be followed (Stefànsson, 1996; Lauria et al., 2011) whereby a binomial occurrence model (obtained through logistic regression) is used to balance a non-null density (or positive) model. The binomial model predicts the probability of presence of the species from input data either coded as presence (1)/absence (0), or from proportions, while the positive model predicts densities from the presence subset of the input data, i.e. sampling points with non-null density. The resulting combined, or delta, model predicts mean density levels for that species.

GLMs are flexible in that they can be applied to data that are not necessarily normally distributed, such as those collected during fishery-independent trawl surveys. This is achieved through a link function that ensures data transformation towards linearity and maintains model predictions within a 
range of values coherent with the original data (Guisan and Zimmermann, 2000). Furthermore, GLMs are suited to cases where there are a large number of zero occurrences in the modelled dataset (Welsh et al., 1996), which is often the case of species sampled during fishery-independent trawl surveys. These surveys, which were designed to optimise the sampling of commercial teleosts, provide some of the only detailed, species-specific information on demersal elasmobranchs (e.g. dogfish, skates and rays) in European waters (Daan et al., 2005; Ellis et al., 2005a,b; Maxwell and Jennings, 2005; Martin et al., 2010), and are also used to evaluate stock status (ICES, 2010b). (1)

The eastern English Channel (Figure 1A) is a shallow sea area, characterised by a heterogeneous environment (Figure 2) that supports feeding, spawning and nursery areas for a number of marine species, including fish (Pawson, 1995; Vaz et al., 2007; Carpentier et al., 2009). The bathymetry slopes down gradually from the coast, and the depths in mid-channel are $60-80 \mathrm{~m}$. The local hypertidal regime (i.e. the tidal range is $>6 \mathrm{~m}$ ), and to a lesser extent winds, result in strong hydrodynamics and alternating currents. The French and UK coastlines contribute to forming steep gradients of tidal amplitude, and current speeds (and associated seabed stress) are greatest where the two coastlines are closest (i.e. the Dover Strait and the "narrows", Figure 1A). These tidal gradients also influence the seabed sediments, with harder substrata (gravel and pebbles) where currents are strong, and softer ones (sand and muddy-sand) in areas more sheltered from strong tidal currents (e.g. some bays). The tidal regime, winds and relatively shallow depths result in a well mixed water column throughout the year, meaning that there is neither a thermocline nor major differences between near bottom and surface temperatures and salinities (Pingree, 1980). Offshore waters in October are slightly warmer than the shallow, coastal areas, and there is an arm of less saline water along the French coast due to freshwater inflow from French rivers (Brunet et al. 1992). The eastern English Channel, and its local biodiversity, are also subject to numerous anthropogenic impacts, including shipping, aggregate extraction, aquaculture and fisheries, and eutrophication (Dauvin, 
2008; Martin et al., 2009). In this context, it is essential to conserve the habitats of sensitive species such as elasmobranchs.

Elasmobranchs are known to be more vulnerable to over-exploitation than many teleost fish, due to the slow population growth resulting from a late age at maturity, longevity, low fecundity and long gestation period (Stevens et al., 2000; Compagno et al., 2005; Ellis et al., 2008). In the English Channel, a number of elasmobranchs are commercially exploited, including thornback ray Raja clavata, blonde ray $R$. brachyura, spotted ray R. montagui and starry smooth-hound Mustelus asterias (Pawson, 1995; Carpentier et al., 2009). Although mainly a by-catch in mixed demersal fisheries, some of the larger skates (e.g. R. clavata) are targeted in some areas (Carpentier et al., 2009). Other species are of conservation interest, for example undulate ray Raja undulata is classed as Endangered by the International Union for the Conservation of Nature (IUCN, 2010). Many elasmobranchs segregate by size and/or sex (e.g. Springer, 1967; Pawson, 1995; Wearmouth and Sims, 2008; Bansemer and Bennett, 2011) or aggregate at ecologically-important habitats (e.g. areas of high prey abundance; Jacoby et al., 2011), meaning that important components of the population (e.g. reproductively active females or juveniles) can be distributed more discretely and so potentially subject to localised over-exploitation (Wearmouth and Sims, 2008). However, little is known about habitat utilization of elasmobranchs in this regional sea.

The present study quantitatively investigated the distribution of ten small demersal elasmobranch taxa (Table 1) in the eastern English Channel in relation to five environmental variables. Data from a fishery-independent bottom trawl survey (collected each October for 21 years) were analysed using a standardized GLM approach coupled with a Geographic Information System (GIS), and environment-based habitat models developed, evaluated and mapped. Model performances were examined in relation to catch frequency, as elasmobranch catches are known to occur at contrasting 
levels in the study area (Ellis et al., 2005a; Martin et al., 2010). For the three most abundant species, sexual and ontogenetic differences in habitat utilization were also investigated.

\section{MATERIAL AND METHODS}

Survey data. Between 1988 and 2008 and under the auspices of the ICES (International Council for the Exploration of the Sea) International Bottom Trawl Survey Working Group (IBTSWG), IFREMER have carried out the fishery-independent Channel Groundfish Survey (CGFS). This trawl survey (described in ICES, 2010a) takes place in the eastern English Channel (ICES Division VIId) and provides data to support the assessment of the main commercial fish stocks in the area.

A total of $60-110$ stations (haul duration $=30$ min hauls; trawl speed $=3.5$ knots) were sampled each October (Figure 1B) on board the $R V$ Gwen-Drez. The gear was a small GOV (Grande Ouverture Verticale) bottom trawl with a high (ca. $3 \mathrm{~m}$ ) headline height and a cod-end liner of 20 $\mathrm{mm}$ (stretched mesh) to catch juveniles. Trawling depth (m) was recorded by sensors on-board the research vessel. Since 1997, SCANMAR sensors (Scanmar AS, Norway) have been used to record and maintain net geometry, and a Micrel (San Jose, CA, USA) hydrological probe (attached to the headline of the trawl) used to measure temperature $\left({ }^{\circ} \mathrm{C}\right)$ and salinity (Practical Salinity Units, PSU) every 15 seconds.

At each trawl station, fish species were sorted, weighed, counted and measured (total length, to the whole cm below for elasmobranchs). Since 1991, elasmobranchs were sexed; sex ratio at individual stations was calculated as the proportion of females $(\% \mathrm{~F})$. Although nominal data for both common smooth-hound Mustelus mustelus and M. asterias were available, it is now accepted that the identification based on presence/absence of spots on the body is unreliable for identification (Farrell et al., 2009). Data on these morphologically similar congeners were combined and analysed as 
151 Mustelus spp., of which M. asterias is the more abundant. Elasmobranch densities, or relative

152 abundance, from a total of 1,828 trawl hauls covering the period 1988 to 2008 , were expressed as

153 numbers of individuals per $\mathrm{km}^{2}$ (ind. $\mathrm{km}^{-2}$ ). For this, swept area was based on a theoretical wing

154 spread of $10 \mathrm{~m}$, which was checked to be close to the average effective wing spread. Survey density

155 data were $\log$-transformed $\left(\log _{10}[\mathrm{x}+1], \mathrm{x}=\right.$ density) to reduce the skewed distribution (Legendre

156 and Legendre, 1998).

157

158 Length at age calculation. Size (total length) was used as a proxy for age. Lengths at age were

159 calculated using the von Bertalanffy (1938) equation:

160

$$
\mathrm{L}_{\mathrm{t}}=\mathrm{L}_{\infty}-\left(\mathrm{L}_{\infty}-\mathrm{L}_{\mathrm{b}}\right) \mathrm{e}^{-k \mathrm{t}}
$$

161 where $L_{t}(\mathrm{~cm})$ is length as a function of time $t$ (year), $\mathrm{L}_{\infty}(\mathrm{cm})$ is the theoretical asymptotic length, $162 \mathrm{~L}_{\mathrm{b}}(\mathrm{cm})$ is the length at birth, and $k\left(\right.$ year $\left.^{-1}\right)$ is the growth rate constant (Cailliet et al., 2006). Based

163 on the estimated lengths at age and length frequency histograms obtained from survey data,

164 densities for the three most abundant species were recalculated for two age groups (neonate and 165 young; sub-adult and adult) and modelled separately.

167 Other datasets used. The 1988-2008 density dataset was partitioned into two subsets (1988-1996 168 and 1997-2008) due to the absence of in situ temperature and salinity data for the first time period.

169 The recent time period was used for model development and internal evaluation, whilst the earlier

170 time period was only used for external model evaluation. Table 2 lists the various datasets used for 171 the main modelling steps: (i) development (and internal evaluation), (ii) mapping of the predictions, 172 and (iii) external evaluation. The depth map (step ii, Figure 2A) merged bathymetry and mean sea 173 level (corresponding to a mid-tide coefficient) derived from a 3D hydrodynamic model (Le Roy and 174 Simon, 2003; Carpentier et al., 2009). Seabed sediment types (steps i to iii, Figure 2B) came from a 175 digital map of the surface sediments in the English Channel, originally developed by Larsonneur et 176 al. (1979), and in which the original 29 sediment classes were aggregated into five broader classes:

Martin et al. 
mud (M), fine sand (FS), coarse sand (CS), gravels $(\mathrm{G})$ and pebbles $(\mathrm{P})$. Bed shear stress (steps i to

178 iii, Figure 2C) came from an 8-km resolution hydrodynamic model developed originally for the

179 Irish Sea (Aldridge and Davies, 1993), but later extended to cover the north-west European shelf.

180 Bed shear stress (Newton. $\mathrm{m}^{-2}$ ) is an estimate of the pressure exerted across the seabed by tidal

181 forcing (M2 constituent) and often influences the distributions of marine species (Freeman and

182 Rogers, 2003). A mean sea surface temperature map was produced for the month of October for the

183 period 1997-2008 (step ii, Figure 2D) using satellite-derived (AVHRR sensor) temperature data

184 (Casey et al., 2010). The same source was used to produce annual maps for each October between

1851988 and 1996 (nine maps in total, step iii). A mean sea surface salinity map for the month of

186 October (steps ii and iii, Figure 2E) was produced by averaging annually interpolated survey maps

187 for the period 1997-2006 (Carpentier et al., 2009).

188

189 Model development. The five environmental variables were not collinear (Variance Inflation

190 Factor < 5; Zuur et al., 2007), and were tested for significant contribution to the models. Depth and

191 sea surface temperature and salinity were those measured in situ during the survey, and seabed

192 sediment type and bed shear stress were derived from Figures $2 \mathrm{~B}$ and C. Seabed sediment types

193 (categorical variable) were introduced to the models as factors (Legendre and Legendre, 1998). The

194 four continuous predictors were tested as first and second order polynomial terms, based on data

195 exploration plots which suggested that the shape of species-environment relationships would often

196 be better described as curvilinear (Austin, 2002). Interactions between first order continuous

197 predictors were also tested.

198

199 Histograms of relative densities indicated that there was recurring discontinuity between the zero

200 values and positive density data, suggesting a two-step modelling approach. Binomial occurrence

201 models were developed using presence-absence data (or proportions for sex ratio models) as the

202 response variable and a logit link function, to predict the mean presence probability of each of the

Martin et al. 
species considered. Positive models were developed using a subset containing only non-null

204 densities and an identity (Gaussian) link function, to predict the mean density on a log scale. The 205 MASS package (version 7.3-5; Venables and Ripley, 2002) in R (R Development Core Team, 206 2009) was used to select the significant variables and to estimate the parameters of the models. 207 Starting from an initial full model, predictors were removed by backward elimination based on 208 Akaike's Information Criterion reduction (AIC; Akaike, 1974).

210 A delta model (combining binomial and positive models) was attempted for each species, as this 211 would reveal which variables influenced its occurrence and density. When the delta model was 212 unsatisfactory (see below for evaluation criteria), only the results of the binomial occurrence model 213 were presented (if satisfactory).

215 Model mapping. Maps of the five environmental variables (Figure 2) were combined with model 216 parameters within a GIS to predict each species' habitat. To illustrate the species response along 217 any given environmental gradient, presence probabilities, or densities, were predicted by each 218 model, whilst keeping all other continuous variables at their mean value. These 'evaluation strips' 219 (Elith et al., 2005; Vaz et al., 2008) were used to examine model behaviour and to help interpret 220 model results, taking into account different seabed sediment types. Model prediction error (or 221 model uncertainty) was computed as the absolute difference between survey and predicted values, relative to the maximum survey value (i.e. a value of 1 corresponded to the maximum possible error in prediction). These errors were spatially auto-correlated and it was possible to estimate them at non-sampled locations using a variogram describing their spatial structure and variation, and to interpolate them by ordinary kriging (Petigas, 2001). In the case of sex ratio models, the binomial occurrence model was used to balance, within a GIS, the corresponding delta model showing both sexes together, to visualize potential spatial segregations by sex, in density levels.

Martin et al. 
Model evaluation. Though a key step in the development of habitat models, model evaluation and validation are not always undertaken (see Manel et al., 2001). Additionally, some studies that have

231 tested models have often used the same data for both model development and evaluation (Olden et 232 al. 2002). Here, models were evaluated internally by directly comparing predictions with survey 233 values for the same time period (1997-2008). To evaluate models externally, predictions were 234 compared with survey values for an earlier time period (1988-1996), the data for which had not 235 been used for model development. For the latter, sea surface temperature data were extracted from 236 the satellite-derived annual maps produced for October between 1988 and 1996. Salinity data were extracted from Figure 2E and corresponded to the second time period (1997-2008), and it was assumed that salinity patterns were not significantly different over the two decade timescale considered.

241 The predictive power of each model was assessed qualitatively using a range of diagnostic plots 242 (Zuur et al., 2007), and also quantitatively. Firstly, a Spearman's rank correlation test investigated 243 whether there was a positive and significant correlation between survey data and predicted values: considered passed if $r_{s} \geq 0.1$ and $p<0.05$ (Carpentier at al., 2009; Lauria et al., 2011). Secondly, the proportion of deviance explained by the models, adjusted for the number of variables in the model, 246 was considered sufficient if adj- $\mathrm{R}^{2} \geq 0.1$ (Carpentier at al., 2009; Lauria et al., 2011), a value 247 deemed suitable for infrequent to moderately abundant species such as elasmobranchs. Finally and 248 for binomial models, the Receiver Operating Characteristic (ROC) curve (Guisan and 249 Zimmermann, 2000) showed the trade off between prediction sensitivity and specificity, and was 250 considered passed if the Area Under the Curve (AUC) $\geq 0.80$ and $p<0.01$. For delta models, a 251 Wilcoxon signed-rank test assessed whether there was a significant difference between survey and 252 predicted values: considered passed if $p \geq 0.05$ (Lauria et al., 2011). Hence, there were three 253 quantitative criteria for each evaluation dataset (internal and external): (i) adj-R ${ }^{2}$, (ii) Spearman's 254 correlation test, and (iii) Wilcoxon signed-rank test or ROC curve. A model was deemed

Martin et al. 
satisfactory if, in addition to suitable diagnostic plots (qualitative evaluation), it passed at least three 256 of the six quantitative evaluations (three internal and three external).

\section{RESULTS}

\section{Input datasets}

261 Of the 1,179 trawl stations sampled from 1997 to 2008 that were available for model development 262 and internal evaluation, in situ temperature and salinity data were missing at 33 stations (2.8\%), due 263 to equipment failure. The remaining 1,146 stations (Table 3) were associated with all five 264 environmental variables (depth, seabed sediment type, bed shear stress, and in situ temperature and 265 salinity).

267 Similarly, of the 649 stations available for external evaluation of the model (time period 1988268 1996), 94 stations (16.7\%) had missing temperature data as a result of cloud cover or proximity to 269 land in the satellite images. Hence, a total of 555 trawl hauls from this time period were used for 270 external model evaluation.

272 In the case of the sex ratio model for lesser-spotted dogfish Scyliorhinus canicula, model 273 development and internal evaluation were carried out on data from 672 stations, and model external evaluation on data from 258 stations. These subsets represented stations where S. canicula occurred.

Habitat modelling by age group (based on the conversion of length data) was undertaken for three species (R. clavata, S. canicula, and Mustelus spp.) for which it was possible to (i) estimate the length at age from published studies (Table 4), and (ii) form two age groups of sufficiently large sample size (based on the length frequency distributions; Figure 3). Where published biological parameters indicated sexual differences (e.g. S. canicula and Mustelus spp., references in Table 4), 
an average length at age was used to identify an appropriate length split between 'neonate and young' and 'sub-adult and adult'. The swimming capabilities and behaviours of smaller and/or 283 younger fish are often markedly different to that of larger, mature individuals, and so the 284 distributions of different cohorts may relate differently to the various physical and biological aspects of their environment, and ontogenetic habitat utilisation can be pronounced. Analyses for $R$. clavata, S. canicula and Mustelus spp. used a length split $\left(\mathrm{L}_{2}\right)$ that equated with two year old fish.

\section{Modelled habitats for all individuals (lengths and sexes combined)}

Six binomial occurrence and four delta habitat models were developed (Tables 5 and 6). Delta habitat models were satisfactorily evaluated for the most frequently occurring species: $R$. clavata (present at $33.5 \%$ of hauls), S. canicula (58.7\% of hauls), greater-spotted dogfish Scyliorhinus stellaris (15.4\% of hauls) and Mustelus spp. (30.5\% of hauls) (Table 3). For the remaining six species, input data for positive models were limited, ranging from 11 positive occurrences $(1.0 \%$ of hauls) for small-eyed ray $R$. microocellata to 54 (4.7\% of hauls) in the case of tope Galeorhinus galeus. Despite these low occurrence levels, six binomial occurrence models were developed and evaluated satisfactorily.

Depth, bed shear stress and salinity were significant predictors of all ten habitat models, whilst seabed sediment type and temperature were important in nine models. Furthermore, the four continuous predictors were often present in the models as second order polynomials, thereby indicating curvilinear relationships. The number of first order interactions retained in the models ranged from one to four. The most frequently selected interaction was that of depth with salinity

303 (selected 13 times), followed by bed shear stress with sea surface temperature, and depth with bed 304 shear stress (both selected 8 times). 
The habitat maps (Figures 4 and 5) and model behaviour (Figure 6 shows the example of $S$.

307 canicula) derived from the model equations help inform on the relationship between each species 308 and the environment of the eastern English Channel (Figure 2). The modelled habitat maps of 309 stingray Dasyatis pastinaca, G. galeus, R. clavata, S. canicula, S. stellaris, and Mustelus spp. 310 (Figures 4A, 4F and 5A-D) revealed that these species preferred the hard sediments (gravel and 311 pebbles) that occurred in the central parts of the survey area and in the Dover Strait (Figure 2B).

312 These coarse grounds coincided with zones of intermediate to strong tidal currents (Figure 2C), and 313 deeper waters (Figure 2A). R. clavata (mostly juveniles) and S. canicula (mostly juveniles and 314 females) also occurred, at lower density levels, on some inshore grounds where seabed sediments 315 were comprised of mud, sand and gravel (Figures 5A and B). In contrast, species such as $R$. 316 brachyura and $R$. microocellata preferred more coastal habitats with soft sediments (muddy sand, 317 fine and coarse sands), located in shallower areas that were sheltered from strong tidal currents 318 (Figures 4B and C). Although the habitats of $R$. montagui and $R$. undulata were similar (Figures 4D 319 and $\mathrm{E}$ ), in that suitable grounds were located both inshore and offshore, $R$. undulata tended to prefer 320 slightly harder sediment types (gravel, pebbles) associated with stronger bed shear stress than $R$. 321 montagui, and also occurred mainly in the western parts of the study area.

323 All ten models presented in Tables 5 and 6 passed at least three of the six evaluation criteria, with $324 R$. montagui passing only three and G. galeus passing all six. Potential relationships between each species' occurrence levels (estimated as the number of positive occurrences relative to the number 326 of trawl stations) and aspects of the performance of the corresponding habitat model were 327 investigated. The proportion of deviance explained by the model and the number of evaluation 328 criteria passed did not correlate significantly with species' occurrence levels (Spearman's 329 correlation, $p>0.05, N=10$ models), suggesting that it was not influenced by how frequently a 330 species had been caught. In contrast, the correlations between survey and predicted values were 331 positive and significantly stronger (i.e. higher $r_{s}$ values) as species increased in occurrence

Martin et al. 
332 (Spearman's correlation, $N=10$ models, $\mathrm{df}=8)$, for both internal $\left(\mathrm{r}_{\mathrm{s}}=0.88, p<0.001\right)$ and external $333\left(\mathrm{r}_{\mathrm{s}}=0.82, p<0.01\right)$ evaluations. Finally, the internal evaluation (time period 1997-2008) passed an 334 average of 2.7 tests (range 2-3), compared to 1.5 (range $0-3$ ) for the external evaluation (time period 335 1988-1996).

Prediction errors associated with each habitat map (Figures 4 and 5) tended to be higher in areas where individuals were caught more frequently, suggesting that density variability in these areas was higher. Conversely, errors were lower in areas where individuals were caught less frequently.

340 This indicated that there was little model uncertainty concerning the extent of the areas where the 341 modelled species was absent.

\section{Modelled habitats by age group}

344 To enable direct comparison across age groups (neonate and young; sub-adult and adult) of $R$. clavata, S. canicula and Mustelus spp., models were presented as binomial occurrence models (Table 7), although some age groups had satisfactory delta models.

The habitat model for sub-adult and adult $R$. clavata (Figure 7B) only passed two evaluation criteria, but was retained for comparison with the model for neonates and young (Figure 7A). The mapped models were almost mirror images of each other, i.e. there was very little overlap between them. The younger age groups occurred primarily in shallow waters along the French and UK coasts, especially in bays (and including areas of slightly lower salinity) where bed shear stress was weak. These areas also coincided with muddy and sandy substrates. In contrast, the habitats of the 354 older age groups were more broadly distributed, including those grounds consisting of harder 355 sediments (gravel, pebbles). These ontogenetic differences in habitat utilization were coherent with 356 the habitat map developed for all individuals (Figure 5A), in which there appeared to be little 357 unsuitable habitat evident across the study area.

Martin et al. 
359 Ontogenetic differences in habitat utilization between neonate and young (Figure 7C) and sub-adult 360 and adult (Figure 7D) S. canicula were less conspicuous. The habitat of the older age group was 361 more broadly distributed than that of the younger age group. Younger fish were usually located on 362 softer sediment types (mud, fine sand), closer to the UK and French coasts, whilst the main habitats 363 of the older age group were located further offshore, on harder bottoms (gravel, pebbles), including 364 the Dover Strait. Both age groups of Mustelus spp. (Figures 7E and F) had suitable habitats located 365 in deep waters with hard bottoms, although the habitat of neonate and young was more broadly 366 distributed, and included the less saline coastal waters where bottom types were softer (muddy367 sand).

\section{Modelled habitats of male and female $S$. canicula}

370 The binomial model predicting the proportion of female $S$. canicula comprised all five tested 371 predictors (Table 7), and passed all six evaluation criteria. The proportion of females was clearly 372 higher in shallow coastal areas, especially along the English coast (Figure 8A). As a result, derived 373 habitat maps showing the density levels of females and males contrasted significantly. Male habitat 374 (Figure 8C) was very similar to the overall habitat (sexes combined, Figure 5B), with the exception 375 of two areas where densities were lower: one south of the Isle of Wight and the other along the coasts of the Dover Strait. It was in these two areas, with coarser substrata, that female densities were at their greatest (Figure 8B). Female were also found at comparatively moderate density levels in the central waters of the eastern English Channel.

\section{DISCUSSION}

382 Groundfish survey data were used to improve our understanding of habitat utilization by ten 383 demersal elasmobranchs in the eastern English Channel, based on a standardized GLM approach

Martin et al. 
using data covering broad temporal and spatial (regional sea) scales. Model parameters helped quantify habitat utilization and reveal important combinations of environmental variables for each species' habitat. The associated habitat maps highlighted contrasting habitat utilization between species. For the first time, a combination of habitat modelling and GIS calculation was used to gain new insights into the spatial ecology of these species in this area, and also in terms of segregation by size (three species) and sex (one species). Despite the zero-inflated nature of some species' datasets, the GLM approach was found to be suitable and relatively straightforward to implement (from model development and evaluation, to mapping), hence providing a practical solution to fisheries managers and conservationists. Modelled habitat maps can be used as inputs in systematic conservation planning (Margules and Pressey, 2000), an approach that is widely used in marine spatial planning, including the design of marine protected area networks in multiple-use areas. Decision-support tools (e.g. Delavenne et al., 2011) often require knowledge of the spatial distribution of the features that are to be conserved, e.g. species and/or habitats. In terms of fisheries management, habitat maps by age could be used to select areas for improved regional management or technical measures (Wiegand et al., 2011).

\section{Modelled habitats for all individuals (lengths and sexes combined)}

The main predictors of elasmobranch habitats in the eastern English Channel in October were depth, bed shear stress and salinity, followed by seabed sediment type and temperature. Spatial habitat models (based on data from 1997 to 2008) were found to be coherent with spatial patterns mapped by geostatistical interpolation based on data from the same survey (period 1988-2008; Martin et al., 2010). Patterns were also consistent with those from other studies reporting on habitat utilization by the various species (e.g. R. brachyura, R. montagui and S. stellaris in Ellis et al., 2005a; R. clavata in Rousset, 1990a, and Hunter et al., 2005; R. undulata in Coelho et al. 2003; S. canicula in Vaz et al., 2008). Earlier studies have observed that Mustelus spp. were abundant in coastal areas with fine sediment types (Ellis et al., 2005a), although this was based primarily on

Martin et al. 
410 observations of juvenile fish, and the trawl survey used in the present study (which also samples

411 larger fish) confirm that coarser grounds are important habitats.

413 The frequency of occurrence of a species was a factor in model performance. Indeed, based on the

414 strength of correlation between predicted and survey values, models performed better for the

415 species that were captured more frequently. Indeed, satisfactory delta models were presented for the

416 four most frequent species, whilst the less frequent species were only shown as binomial occurrence

417 models. This was because positive models were based on significantly smaller input datasets,

418 making it difficult to obtain a satisfactory combined model, whilst in a binomial occurrence model,

419 even zeros provide information (i.e. the species was not captured at these locations).

421 Internal evaluation passed more evaluation tests than external evaluation. It is likely that several

422 factors contributed to this difference in performance. Firstly, external evaluation was based on an 423 input dataset (555 trawl stations) that was smaller than that used for internal evaluation (1,146 trawl

424 stations). Secondly, as in situ salinity data were not available in the external evaluation dataset, 425 salinities from the time period 1997 to 2008 (the period for model development and internal 426 evaluation) were used, and it was not possible to assess how much uncertainty was introduced as a 427 result. Finally, some species showed changes in occurrence and/or density level over time (Martin 428 et al., 2010), with possible effects on associated internal and external model evaluations.

\section{Modelled habitats by age group}

431 Of the three species for which possible ontogenetic differences in habitat utilization were 432 investigated, such shifts were clearer for R. clavata compared to S. canicula and Mustelus spp. 433 Given the published lengths at 50\% maturity (Table 4) and length frequency histograms (Figure 3), 434 each of the two groups contained multiple age classes. The younger one contained neonates and 435 young juveniles, whilst the older group contained older juveniles, sub-adult and adult fish.

Martin et al. 
Consequently, these ontogenetic differences in habitat utilization were related to size (total length) and not maturity status. Modelling results suggested that the younger age groups of $R$. clavata and

438 S. canicula were found in shallow coastal waters, sheltered from strong tidal currents and where 439 seabed sediment types were soft (mud and sand). This was consistent with previous studies in this 440 area and elsewhere (Rousset, 1990b, and Ellis et al., 2005a, for R. clavata; Compagno, 1984, and 441 Carpentier et al., 2009 for S. canicula). Young fish are likely to be limited in their swimming and 442 competitive abilities, and vulnerable to predators in unsuitable habitats (Jacoby et al., 2011). This is 443 consistent with the results presented here, whereby shallow, coastal waters may offer protection 444 against predation, ample food resources (including smaller prey items) and typically with warmer 445 water to encourage growth (Springer, 1967; Speed et al., 2010). Data presented here are insufficient 446 to conclude that these locations were "nursery" areas for these two species, given that not all areas 447 where juveniles occur can be considered nursery areas (Heupel et al., 2007). It should be noted that egg-cases of $S$. canicula and recently-hatched fish are caught on the hard ground south of the Isle of

449 Wight (Ellis et al., 2005a), as the egg cases are often laid on sessile, filter-feeding invertebrates 450 (Ellis and Shackley, 1997). Hence, there may also be different patterns in the habitat utilization of 451 recently-hatched fish and larger juveniles. Results for Mustelus spp. did not show any major 452 ontogenetic difference in habitat utilization, although juveniles were more abundant in shallow, 453 coastal environments. S. stellaris was the fourth most abundant species during the period of survey. 454 The egg-cases are known to occur in some inshore areas elsewhere around the British Isles, and the 455 youngest fish are only caught occasionally in groundfish surveys (Ellis et al., 2005a). The lack of 456 length at age data for this species prevented further analysis.

\section{Modelled habitats of male and female S. canicula}

459 S. canicula showed clear spatial segregation by sex with higher proportions of females in shallow 460 coastal waters, and on some of the harder grounds (e.g. south of the Isle of Wight). Segregation of 461 S. canicula by sex has been reported to operate over both small (Sims et al., 2001; Sims, 2003) and

Martin et al. 
larger scales (Rodriguez-Cabello et al., 2007; Martin et al., 2010). When proportions were brought back to density levels, results presented here suggested that segregation could be at least partly habitat-based (Wearmouth and Sims, 2008), i.e. that there were sexual differences in this species' response to variability in environmental conditions, and possibly resource availability, although the latter could not be tested directly in the modelling procedure. Female $S$. canicula have a protracted egg-laying season (Ellis and Shackley, 1997), and egg-cases are often laid on macroalgae (in coastal waters) and on sessile invertebrates (offshore). Although the present study found that female $S$. canicula were often in inshore areas, the main sites of high female abundance were near areas of hard (mainly gravel) grounds (e.g. south of the Isle of Wight, along the coasts of the Dover Strait), and so the distribution of females could be related to proximity to potential oviposition areas and also as a refuge from male harassment (Sims et al., 2001).

\section{Conclusion}

One of the necessary elements for the development of coherent marine strategies is the assessment of species distributions and habitats, and such information is an important element of the European Marine Strategy Framework Directive (European Commission, 2010). There is a specific need to make sure that important habitats are of sufficient extent and quality to maintain viable stock, taking into consideration any threats of habitat degradation (e.g. through dredging, aggregate extraction, pollution), from human exploitation (fisheries) and from environmental change. An improved knowledge of the habitat utilization of elasmobranchs (and by their life history stages) is required for the improved management of both commercial stocks and species of conservation interest (Ellis et al., 2008; Speed et al., 2010), and the present study highlighted some of the key areas for the main species during October in the eastern English Channel. Data on seasonal differences in the distributions of elasmobranchs are limited, both for the study area and elsewhere. An earlier study examined the spatial distributions of a variety of fish species in the eastern English Channel, 
488

including $R$. clavata, R. montagui, S. canicula and S. stellaris, from surveys undertaken in July and October (Carpentier et al., 2009), which suggested fairly stable distribution patterns at these times of year. Although the present study was limited to October, and R. clavata in the southern North Sea have been shown to display seasonal migrations (Hunter et al., 2005), it is considered that the present study should highlight the broad habitat utilization of the demersal species studied, although further studies for the more mobile and migratory species, such as the triakids, are certainly warranted.

Acknowledgments: Part of the work was co-financed by the European Union through its European Regional Development Fund (INTERREG 3a CHARM II project 162/039/365). The authors would like to thank the GENAVIR crew and scientific staff of the research vessel Gwen-Drez. The authors are grateful to F. Gohin (IFREMER Brest) and B. Saulquin (Telecom Bretagne) for the sea surface temperature satellite data, to K. Urbantat for English language editing, and to two reviewers for their comments and suggestions. CSM carried out some of the work with funding from the European Union (MC FP7-PEOPLE-IEF-2008, grant 235791).

\section{REFERENCES}

Akaike, H., 1974. A new look at the statistical model identification. IEEE T. Automat. Contr. 19, $716-723$.

Aldridge, J.N., Davies, A.M., 1993. A high-resolution three-dimensional hydrodynamic tidal model of the Eastern Irish Sea. J. Phys. Oceanogr. 23: 207-224.

Austin, M.P., 2002. Spatial prediction of species distribution: an interface between ecological theory and statistical modelling. Ecol. Model. 157: 101-118. 
Bansemer, C.S., Bennett, M.B., 2011. Sex- and maturity-based differences in movement and migration patterns of grey nurse shark, Carcharias taurus, along the eastern coast of Australia. Mar. Freshwater Res. 62: 596-606

Brunet, C., Brylinski, J.M., Frontier S., 1992. Productivity, photosynthetic pigments and hydrology in the coastal front of the Eastern English Channel. J. Plankton Res. 14: 1541-1552.

Cailliet, G.M., Smith, W.D., Mollet, H.F., Goldman, K.J., 2006. Age and growth studies of chondrichthyan fishes: the need for consistency in terminology, verification, validation, and growth function fitting. Environ. Biol. Fish. 77: 211-228.

Carpentier, A., Martin, C.S., Vaz, S. (Eds.), 2009. Channel Habitat Atlas for marine Resource Management (CHARM phase II), INTERREG 3a Programme. IFREMER, Boulogne-surmer. http://archimer.ifremer.fr/doc/2009/rapport-7377.pdf

Casey, K.S., Brandon, T.B., Cornillon, P., Evans, R., 2010. The past, present and future of the AVHRR Pathfinder SST program. In: Barale, V., Gower, J.F.R., Albertotanza, L. (Eds.), Oceanography from space: revisited. Springer, Dordrecht, pp. 323-340.

Coelho, R., Bertozzi, M., Ungaro, N., Ellis, J.R., 2003. Raja undulata. In: IUCN, 2009, Red list of threatened species version 2009.2. Accessed 04 Jul 2011. www.iucnredlist.org

Compagno, L.J.V., 1984. FAO Species Catalogue, Vol. 4, Sharks of the World, Parts 1 and 2. Food and Agriculture Organisation of the United Nations, Rome.

Compagno, L.J.V., Dando, M., Fowler, S.L., 2005. Sharks of the World. Harper Collins, London.

Daan, N., Heessen, H., ter Hofstede, R., 2005. North Sea elasmobranchs: distribution, abundance and biodiversity. In: Proc. ICES Ann. Sc. Conf. CM 2005/N:06. ICES, Copenhagen

Dauvin, J.C., 2008. The main characteristics, problems, and prospects for western European coastal seas. Mar. Pollut. Bull. 57: 22-40.

Delavenne J., Metcalfe K., Smith R.J., Vaz S., Martin C.S., Dupuis L., Carpentier A., 2011. Systematic conservation planning in the eastern English Channel: comparing the Marxan and Zonation decision-support tools. ICES J. Mar. Sci. doi:10.1093/icesjms/fsr180

Martin et al. 
Elith, J., Leathwick, J.R., 2009. Species distribution models: ecological explanation and prediction across space and time. Annu. Rev. Ecol. Evol. Syst. 40: 677-697.

Elith J., Ferrier S., Huettmann F., Leathwick J., 2005.The evaluation strip: A new and robust method for plotting predicted responses from species distribution models. Ecol. Model. 186, 280-289.

Elith, J., Graham, C.H., Anderson, R.P., Dudik, M., Ferrier, S., and 22 co-authors, 2006. Novel methods improve prediction of species' distributions from occurrence data. Ecography 29: 129-151.

Ellis, J.R., Clarke, M.W., Cortés, E., Heessen, H.J.L., Apostolaki, P., Carlson, J.K., Kulka, D.W., 2008. Management of elasmobranch fisheries in the North Atlantic. In: Payne, A.I.L., Cotter, A.J., Potter, E.C.E. (Eds.), Advances in Fisheries Science. 50 years on from Beverton and Holt. Blackwell Publishing, Oxford, pp. 184-228.

Ellis, J.R., Cruz-Martinez, A., Rackham, B.D., Rogers, S.I., 2005a. The distribution of chondrichthyan fishes around the British Isles and implications for conservation. J. Northwest Atl. Fish. Soc. 35: 195-213.

Ellis, J.R., Dulvy, N.K., Jennings, S., Parker-Humphreys, M., Rogers, S.I., 2005b. Assessing the status of demersal elasmobranchs in UK waters: a review. J. Mar. Biol. Ass. UK 85: 10251047.

Ellis, J.R., Shackley, S.E., 1997. The reproductive biology of Scyliorhinus canicula in the Bristol Channel, UK. J. Fish Biol. 51: 361-372.

European Commission (2010). Commission decision of 1/9/2010 on criteria and methodological standards on good environmental status of marine waters. Annex: Criteria and methodological standards for good environmental status. Official Journal of the European Union L232: 14-24.

Farrell, E.D., Clarke, M.W., Mariani, S. (2009). A simple genetic identification method for Northeast Atlantic smoothhound sharks (Mustelus spp.). ICES J. Mar. Sci. 66: 561-565.

Martin et al. 
Fischer, M., Schneider, M., Bauchot, M.L. (Eds.), 1987. Fiches FAO d'identification des espèces pour les besoins de la pêche. Méditerranée et mer Noire, zone de pêche 37, révision 1, Vol. II. FAO, Rome.

Freeman, S.M., Rogers, S.I., 2003. A new analytical approach to the characterisation of macroepibenthic habitats: linking species to the environment. Estuar. Coast. Shelf S. 56, 749-764.

Goosen, A.J.J. Smale, M.J., 1997. A preliminary study of age and growth of the smooth-hound shark Mustelus mustelus (Triakidae). S. Afr. J. Mar. Sci. 18: 85-91.

Guisan, A., Thuiller, W., 2005. Predicting species distribution: offering more than simple habitat models. Ecol. Lett. 8: 993-1009.

Guisan, A., Zimmermann, N., 2000. Predictive habitat distribution models in ecology. Ecol. Model. 135: $147-186$.

Heupel, M.R., Carlson, J.K., Simpfendorfer, C.A., 2007. Shark nursery areas: concepts, definition, characterization and assumptions. Mar. Ecol.-Prog. Ser. 337: 287-297.

Hunter, E., Buckley, A.A., Stewart, C., Metcalfe, J.D., 2005. Migratory behaviour of the thornback ray, Raja clavata L., in the southern North Sea. J. Mar. Biol. Assoc.UK 85: 1095-1105.

Hutchinson, G.E., 1957. Concluding remarks. Cold Spring Harb. Symp. Quant. Biol. 22: 415-427.

ICES, 1997. Report of the study group on elasmobranchs. ICES Counc. Meet. Pap. 1997/G:2. ICES, Copenhagen.

ICES, 2010a. Report of the International Bottom Trawl Survey Working Group (IBTSWG), 22-26 March 2010, Lisbon, Portugal. ICES CM 2010/SSGESST:06, 267 pp. + Addendum II: Manual for the International Bottom Trawl Surveys in the Western and Southern Areas, Revision III, 58 pp.

ICES, 2010b. Report of the Working Group on Elasmobranch Fishes (WGEF), 22-29 June 2010, Horta, Portugal. ICES CM 2010/ACOM:19, 558 pp.

IUCN, 2010. IUCN Red List of threatened species, version 2010.1. Accessed 04 Jul 2011. www.iucnredlist.org

Martin et al. 
Ivory, P., Jeal, F., Nolan, C.P., 2005. Age determination, growth and reproduction in the lesserspotted dogfish, Scyliorhinus canicula (L.). J. Northwest Atl. Fish. Sci., 35: 89-106.

Jacoby, D.M.P., Croft, D.P., Sims, D.W., 2011. Social behaviour in sharks and rays: analysis, patterns and implications for conservation. Fish Fisheries. doi: 10.1111/j.14672979.2011.00436.x

Larsonneur, C., Vaslet, D., Auffret, J.-P., 1979. Les Sédiments Superficiels de la Manche, carte community: a consequence of differential fishing effects on species with contrasting life histories. J. Anim. Ecol. 68: 617-627.

Jennings, S., Greenstreet, S.P.R., Reynolds, J.D., 1999. Structural change in an exploited fish Géologique de la Marge Continentale Française. Orléans: Bureau des Recherches Géologiques et Minières.

Lauria, V., Vaz, S., Martin, C.S., Mackinson, S., Carpentier, A.,2011. What influences European plaice (Pleuronectes platessa) distribution in the eastern English Channel? Using habitat modelling and GIS to predict habitat utilization. ICES J. Mar. Sci. 68: 1500-1510.

Le Roy, R., Simon, B., 2003. Réalisation et validation d'un modèle de marée en Manche et dans le Golfe de Gascogne. Rapport d'étude 02/03, septembre 2003. Service Hydrographique et Océanographique de la Marine SHOM, Brest.

Legendre, P., Legendre, L., 1998. Numerical ecology. Elsevier, Amsterdam.

Manel, S., Williams, H.C., Ormerod, S.J., 2001. Evaluating presence-absence models in ecology: the need to account for prevalence. J. Appl. Ecol. 38: 921-931.

Margules, C.R., Pressey, R.L., 2000. Systematic conservation planning. Nature 405: 243-253.

Martin, C.S., Carpentier, A., Vaz, S., Coppin, F., Curet, L., and 22 co-authors, 2009. The Channel Habitat Atlas for marine Resource Management (CHARM): an aid for planning and decision-making in an area under strong anthropogenic pressure. Aquat. Living. Resour. 22: 499-508. 
Martin, C.S., Vaz, S., Ellis, J.R., Coopin, F., Le Roy, D., Carpentier, A., 2010. Spatio-temporal patterns in demersal elasmobranchs from trawl surveys in the eastern English Channel (1988-2008). Mar. Ecol.Prog. Ser. 417: 211-228.

Maxwell, D., Jennings, S., 2005. Power of monitoring programmes to detect decline and recovery of rare and vulnerable fish. J. Appl. Ecol. 42: 5-37.

McCullagh, P., Nelder, J.A., 1989. Generalized linear models, monographs on statistics and applied probability 37, 2nd ed. Chapman and Hall, London.

Olden, J.D., Jackson, D.A. \& Peres-Neto, P.R. (2002) Predictive models of fish species distributions: a note on proper validation and chance predictions. Trans. Am. Fish. Soc. 131: 329-336.

Pawson, M.G., 1995. Biogeographical identification of English Channel fish and shellfish stocks. Fish. Res. Tech. Rep. 99. Cefas, Lowestoft. http://www.cefas.co.uk/Publications/techrep/tech99.pdf

Petitgas, P., 2001. Geostatistics in fisheries survey design and stock assessment: models, variances and applications. Fish Fisheries 2: 231-249.

Pingree, R.D., 1980. Chapter 13. Physical Oceanography of the Celtic Sea and English Channel. In: Banner, F.T., Collins, M.B., Massie, K.S. (Eds.), The north-west European shelf seas: the sea bed and the sea in motion II. Physical and chemical oceanography, and physical resources, 24, Part B: 415-465

Planque, B., Loots, C., Petitgas, P., Lindstrom, U., Vaz, S., 2011. Understanding what controls the spatial distribution of fish populations using a multi-model approach. Fish. Oceanogr. 20: 117

R Development Core Team, 2009. R: A language and environment for statistical computing. R Foundation for Statistical Computing, Vienna. ISBN 3-900051-07-0, URL http://www.Rproject.org. 
Ramirez-Bastida, P., Navarro-Siguenza, A.G., Peterson, A.T. (2008). Aquatic bird distributions in Mexico: designing conservation approaches quantitatively. Biodivers. Conserv. 17: 25252558.

Rodriguez-Cabello, C., Sanchez, F., Olaso, I., 2007. Distribution patterns and sexual segregations of Scyliorhinus canicula (L.) in the Cantabrian Sea. J. Fish Biol. 70: 1568-1586.

Rousset, J., 1990a. Catches and geographical distribution of selachians on the western coast of Brittany. J. Mar. Biol. Assoc.UK 70: 255-260.

Rousset, J, 1990b. Population structure of thornback rays Raja clavata and their movement in the Bay of Douarnenez. J. Mar. Biol. Assoc.UK 70: 261-268.

Seo. C., Thorne, J.H., Hannah, L., Thuiller, W., 2009. Scale effects in species distribution models: implications for conservation planning under climate change. Biol. Lett. 5: 39-43.

Sims, D.W., 2003. Tractable models for testing theories about natural strategies: foraging behaviour and habitat selection of free-ranging sharks. J. Fish Biol. 63A: 53-73.

Sims, D.W., Nash, J.P., Morritt, D., 2001. Movements and activity of male and female dogfish in a tidal sea lough: alternative behavioural strategies and apparent sexual segregation. Mar. Biol. 139: 1165-1175.

Speed, C.W., Field, I.C., Meeken, M.G., Bradshaw, C.J.A., 2010. Complexities of coastal shark movements and their implications for management. Mar. Ecol.-Prog. Ser. 408: 275-293.

Springer, S., 1967. Social organization of shark populations. In: Gilbert, P.W., Mathewson, R.F., Rall, D.P. (Eds.), Sharks, skates and rays. Johns Hopkins Press, Baltimore.

Stefànsson, G., 1996. Analysis of groundfish survey abundance data: combining the GLM and delta approaches. ICES J. Mar. Sci. 53: 577-588.

Stevens, J.D., Bonfil, R., Dulvy, N.K., Walker, P., 2000. The effects of fishing on sharks, rays and chimaeras (chondrichthyans), and the implications for marine ecosystems. ICES J. Mar. Sci. 57: 476-494. 

688

Thuiller, W., Lavorel, S., Araujo, M.B., Sykes, M.T., Prentice, I.C., 2005. Climate change threats to plant diversity in Europe. P. Natl. Acad. Sci. USA 102: 8245-8250.

Vaz, S., Carpentier, A., Coppin, F., 2007. Eastern English Channel fish assemblages: measuring the structuring effect of habitats on distinct subcommunities. ICES J. Mar. Sci. 64: 271-287.

Vaz, S., Martin, C.S., Eastwood, P., Ernande, B., Carpentier, A., Meaden, G.J., Coppin, F., 2008. Modelling species distributions using regression quantiles. J. Appl. Ecol. 45: 204-217.

Venables,W.N., Ripley, B.D., 2002. Modern Applied Statistics with S, 4th ed. Springer, New York. von Bertalanffy, L., 1938. A quantitative theory of organic growth. (Inquiries on growth laws II). Hum. Biol. 10: 181-213.

Walker, P.A., 1999. Fleeting images: dynamics of North Sea ray populations, PhD dissertation, University of Amsterdam, Amsterdam.

Wearmouth, V.J., Sims, D.W., 2008. Sexual segregation in marine fish, reptiles, birds and mammals: behaviour patterns, mechanisms and conservation implications. Adv. Mar. Biol. $54,107-170$.

Welsh, A.H., Cunningham, R.B., Donnelly, C.F., Lindenmayer, D.B., 1996. Modelling the abundance of rare species: statistical models for counts with extra zeros. Ecol. Model. 88: 297-308.

Whitehead, P.J.P., Bauchot, M.L., Hureau, J.-C., Nielsen, J., Tortonese, E. (Eds.), 1986. Fishes of the North-eastern Atlantic and Mediterranean, Vol. I. UNESCO, Paris.

Wiegand, J., Hunter, E., Dulvy, N.K., 2011. Are spatial closures better than size limits for halting the decline of the North Sea thornback ray, Raja clavata? Mar Freshw Res 62, 722-733.

Zuur, A.F., Ieno, E.N., Smith, G.M., 2007. Analysing Ecological Data. Springer, New York. 
690 Table 1. Elasmobranch species captured during the Channel Groundfish Survey (CGFS, 1988691 2008) and for which habitat models are presented.

692

$\begin{array}{lllll}693 & \text { Family } & \text { Scientific name } & \text { Species authority } & \text { Common name } \\ 694 & \text { Dasyatidae } & \text { Dasyatis pastinaca } & \text { (Linnaeus, 1758) } & \text { Common stingray } \\ 695 & \text { Rajidae } & \text { Raja brachyura } & \text { Lafont, 1873 } & \text { Blonde ray } \\ 696 & & \text { Raja clavata } & \text { Linnaeus, 1758 } & \text { Thornback ray, roker } \\ 697 & & \text { Raja microocellata } & \text { (Montagu, 1818) } & \text { Small-eyed ray } \\ 698 & & \text { Raja montagui } & \text { Fowler, 1910 } & \text { Spotted ray } \\ 699 & & \text { Raja undulata } & \text { Lacepède, 1802 } & \text { Undulate ray } \\ 700 & \text { Scyliorhinidae } & \text { Scyliorhinus canicula } & \text { (Linnaeus, 1758) } & \text { Lesser-spotted dogfish } \\ 701 & & \text { Scyliorhinus stellaris } & \text { (Linnaeus, 1758) } & \text { Greater-spotted dogfish } \\ 702 & \text { Triakidae } & \text { Galeorhinus galeus } & \text { (Linnaeus, 1758) } & \text { Tope } \\ 703 & & \text { Mustelus } \text { spp. } & & \text { Smooth-hound }\end{array}$


705 Table 2. Datasets used during modelling, and their sources. CGFS: Channel Groundfish Survey.

706

707

Dataset

Model development

(\& internal evaluation)

\section{Model}

mapping

Prediction by habitat model

Hydrodynamic model $^{\mathrm{a}}$

Digital map ${ }^{b}$

Hydrodynamic model ${ }^{\mathrm{c}}$

Satellite data $1997-2008^{\mathrm{d}}$

CGFS 1997-2008
External model

evaluation

CGFS 1988-1996

CGFS 1988-1996

Digital map ${ }^{b}$

Hydrodynamic model ${ }^{c}$

Satellite data $1988-1996^{\mathrm{d}}$

CGFS 1997-2008

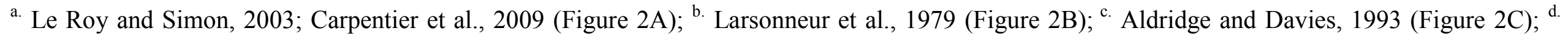

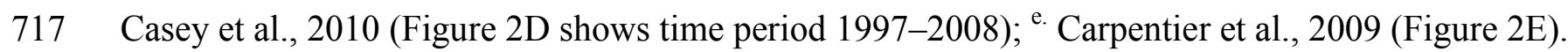


720 Table 3. Details of the analyses undertaken for the ten elasmobranch taxa, giving the number of

721 trawl hauls that could be associated with a full set of environmental variables for model

722 development and internal evaluation, and for external evaluation of the model. Hauls: total number

723 of trawl hauls; Present: number of hauls in which the species occurred (and percentage of total hauls

724 in parentheses). Analyses were undertaken for all individuals, with additional analyses undertaken

725 by age group for Raja clavata, Scyliorhinus canicula and Mustelus spp. (0-1 group: neonate and

726 young; 2+ group: sub-adult and adult). For $S$. canicula, the number of trawl hauls where sex

727 information was available is also given.

\section{Scientific}

Dataset

type

730

731

732

733

734

735

736

737

738

739

740

741

742

743

744

745

746

747

S. stellaris

All

All
Model development \& internal

evaluation (1997-2008)

Hauls

1,146

1,146

1,146

1,146

1,146

1,146

1,146

1,146

1,146

1,146

1,146

$2+$ group

Sex (\%Females) 672

1,146

1,146

1,146

1,146

1,146

$2+$ group
253

Present (\%)

$28 \quad(2.4 \%)$

$31 \quad(2.7 \%)$

384

$(33.5 \%)$

124

$(10.8 \%)$

$309 \quad(26.9 \%)$

$11 \quad(1.0 \%)$

$33 \quad(2.9 \%)$

43

$(3.8 \%)$

$673 \quad(58.7 \%)$

22

$(1.9 \%)$

670

$(58.5 \%)$

542

$(80.7 \%)$

(15.4\%)

$(4.7 \%)$

$350 \quad(30.5 \%)$

193

$(16.8 \%)$

$(22.1 \%)$

\section{Model external evaluation}

(1988-1996)

Hauls

Present (\%)

555

18

(3.2\%)

555

555

555

555

555

555

555

555

555

555

258

555

555

555

555

555
63

182

42

153

2

45

21

329

6

328

183

72

53

87

38
(11.4\%)

$(0.4 \%)$

$(8.1 \%)$

$(13.0 \%)$

$(9.5 \%)$

(15.7\%)

$(6.8 \%)$

Martin et al. 
749 Table 4. Parameters used to calculate length at age using the von Bertalanffy equation: length at

750 birth $\left(\mathrm{L}_{\mathrm{b}}, \mathrm{cm}\right)$, growth rate constant $\left(k\right.$, year $\left.^{-1}\right)$ and theoretical asymptotic length $\left(\mathrm{L}_{\infty}, \mathrm{cm}\right)$. See text

751 for details of the calculations. [F]: female, $[\mathrm{M}]$ : male, $[\mathrm{F} \& \mathrm{M}]$ : female and male; $\mathrm{L}_{2}$ : estimated

752 length at two years old; bold font: length split value used to investigate age group differences in

753 habitat utilization; *: mean of female and male values; $\uparrow:$ the parameters of Mustelus mustelus were

754 used for Mustelus spp.; $\mathrm{L}_{\mathrm{m}}$, the length at 50\% maturity, is given for information.

755

$\begin{array}{llllllll}756 & \text { Scientific name } & \mathbf{S e x} & \mathbf{L}_{\mathbf{b}} & \boldsymbol{k} & \mathbf{L}_{\infty} & \mathbf{L}_{2} & \mathbf{L}_{\mathbf{m}}\end{array}$

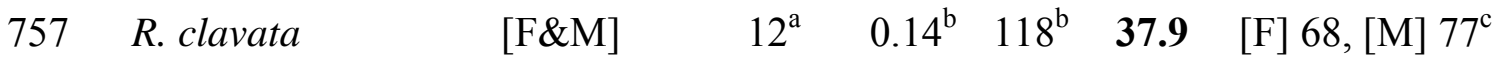

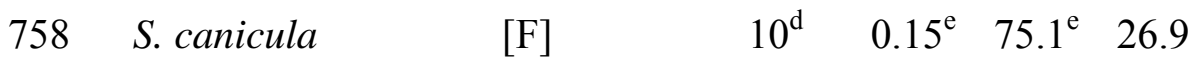

759

$\left[\begin{array}{llll}\mathrm{M} & 10^{\mathrm{a}} \quad 0.12^{\mathrm{e}} & 87.4^{\mathrm{e}} & 26.3\end{array}\right.$

760

$[\mathrm{F} \& \mathrm{M}] \quad \mathbf{2 6 . 6}^{*} 58^{\mathrm{f}}$

$761 \quad$ Mustelus spp. $\oplus^{\dagger} \quad[\mathrm{F}] \quad 22^{\mathrm{a}} \quad 0.06^{\mathrm{g}} \quad 205^{\mathrm{g}} \quad 57.8$

762

$[\mathrm{M}] \quad 22^{\mathrm{a}} \quad 0.12^{\mathrm{g}} \quad 145^{\mathrm{g}} \quad 61.6$

763

$[\mathrm{F} \& \mathrm{M}]$

59.7* $80^{\mathrm{h}}$

764

$765{ }^{a}$ Ellis et al. 2005b (northeast Atlantic); ${ }^{\mathrm{b}}$ ICES 1997 (northeast Atlantic); ${ }^{\mathrm{c}}$ Walker 1999 (northeast 766 Atlantic); ${ }^{\mathrm{d}}$ Whitehead et al. 1986 (northeast Atlantic and Mediterranean); ${ }^{\mathrm{e}}$ Ivory et al. 2005 767 (northeast Atlantic); ${ }^{\mathrm{f}}$ Jennings et al. 1999 (northeast Atlantic); ${ }^{\mathrm{g}}$ Goosen et al. 1997 (southeast 768 Atlantic); ${ }^{\text {h }}$ Fischer et al. 1987 (Mediterranean).

Martin et al. 
Table 5. Selected models for six demersal elasmobranchs (lengths and sexes combined; maps in Figures 4) using binomial occurrence models. Predictors include depth (DEP); mud (M), fine sand (FS), gravel (G) and pebbles (P) seabed sediment types (listed from the highest to lowest coefficients); bed shear stress (STR); sea surface temperature (SST) and salinity (SAL). Predictors suffixed '2' indicate significant second order polynomials, and 'inter.' indicates interactions between model predictors. Models evaluated by the adjusted proportion of deviance explained (Adj- $\mathrm{R}^{2}$ ), Spearman's rank correlation test (coefficient $r_{s}$ ), and Receiver Operating Characteristic (ROC) and Area Under the Curve (AUC). Significance value of statistical tests ( $p$ ) given as ***: $p<0.001, * *: p<0.01, *: p<0.05$. Scores of internal (int.) and external (ext.) model evaluations (out of three) also given (see main text for details). A model was deemed satisfactory if, in addition to suitable diagnostic plots, it passed at least three of the six evaluations (three internal and three external).

\begin{tabular}{|c|c|c|}
\hline \multirow{3}{*}{$\begin{array}{l}\text { Scientific } \\
\text { name }\end{array}$} & \multicolumn{2}{|r|}{ Model selection } \\
\hline & Dataset & Significant \\
\hline & type & predictors \\
\hline D. pastinaca & All & DEP, M-G-FS-P, STR, SST2, SAL, 2 inter. \\
\hline R. brachyura & All & DEP2, G-FS-M-P, STR2, SST, SAL, 3 inter. \\
\hline R. microocellata & All & DEP2, STR2, SST2, SAL, 4 inter. \\
\hline R. montagui & All & DEP2, FS-G-P-M, STR, SST2, SAL, 4 inter. \\
\hline R. undulata & All & DEP2, P-G-FS-M, STR2, SAL, 1 inter. \\
\hline G. galeus & All & DEP2, FS-P-G-M, STR, SST, SAL2, 2 inter. \\
\hline
\end{tabular}

\begin{tabular}{llllllll}
\multicolumn{9}{c}{ Model evaluation } & & & \\
\multicolumn{2}{l}{ Evaluation } \\
Adj-R & \multicolumn{2}{l}{ Spearman's } & ROC & \multicolumn{2}{c}{ Type } & Score \\
& $\mathbf{r}_{\text {s }}$ & $\boldsymbol{p}$ & AUC & $\boldsymbol{p}$ & \multicolumn{2}{l}{} \\
0.20 & 0.19 & $* * *$ & 0.86 & $* * *$ & int. & $3 / 3$ \\
0.07 & 0.15 & $* * *$ & 0.74 & $* * *$ & ext. & $1 / 3$ \\
0.12 & 0.17 & $* * *$ & 0.81 & $* * *$ & int. & $3 / 3$ \\
0.07 & 0.11 & $* *$ & 0.77 & $* *$ & ext. & $1 / 3$ \\
0.47 & 0.16 & $* * *$ & 0.97 & $* * *$ & int. & $3 / 3$ \\
0.22 & 0.06 & 0.10 & 0.76 & 0.09 & ext. & $1 / 3$ \\
0.15 & 0.18 & $* * *$ & 0.81 & $* * *$ & int. & $3 / 3$ \\
0.07 & 0.09 & 0.02 & 0.59 & $*$ & ext. & $0 / 3$ \\
0.14 & 0.20 & $* * *$ & 0.81 & $* * *$ & int. & $3 / 3$ \\
0.02 & 0.19 & $* * *$ & 0.78 & $* * *$ & ext. & $1 / 3$ \\
0.26 & 0.27 & $* * *$ & 0.87 & $* * *$ & int. & $3 / 3$ \\
0.10 & 0.37 & $* * *$ & 0.86 & $* * *$ & ext. & $3 / 3$
\end{tabular}

Martin et al. 
794 Table 6. Selected models for four demersal elasmobranchs (lengths and sexes combined; maps in Figure 5) using delta models. Predictors, listed in

795 Table 5, are given for the binomial (top line) and positive (second line) components. Models evaluated by the adjusted proportion of deviance 796 explained $\left(A d j-R^{2}\right)$, Spearman's rank correlation test (coefficient $r_{s}$ ) and Wilcoxon signed-rank test. Significance value of statistical tests $(p)$ given as $797 * * *: p<0.001, * *: p<0.01, *: p<0.05$. Scores of internal (int.) and external (ext.) model evaluations (out of three) also given (see main text for 798 details). A model was deemed satisfactory if, in addition to suitable diagnostic plots, it passed at least three of the six evaluations (three internal and 799 three external).

800

801

802

803

804

805

806

807

808

809

810

811

812

813

\author{
Model selection \\ Significant \\ predictors \\ DEP2, G-P-M-FS, STR, SAL2, 1 inter. \\ / DEP, STR2, SST, SAL2, 1 inter. \\ DEP, P-G-M-FS, STR2, SST, SAL2, 2 inter. \\ / DEP, G-FS-P-M, STR, SST, SAL2, 4 inter. \\ DEP2, G-P-M-FS, STR2, SST2, SAL2, 1 inter. \\ / DEP2, G-P-FS-M, STR2, SAL2 \\ DEP, P-G-M-FS, STR2, SST2, SAL2, 2 inter. \\ / DEP, M-P-FS-G, STR2, SAL, 1 inter.
}

\begin{tabular}{lllllll}
\multicolumn{3}{c}{ Model evaluation } & & & \\
Adj-R & \multicolumn{2}{l}{ Spearman's } & Wilcoxon & \multicolumn{2}{l}{ Evaluation } \\
& $\mathbf{r}_{\mathbf{s}}$ & $\boldsymbol{p}$ & $\boldsymbol{p}$ & Type & Score \\
0.05 & 0.25 & $* * *$ & 0.36 & int. & $2 / 3$ \\
0.04 & 0.24 & $* * *$ & 0.21 & ext. & $2 / 3$ \\
0.32 & 0.59 & $* * *$ & 0.98 & int. & $3 / 3$ \\
0.34 & 0.52 & $* * *$ & $* * *$ & ext. & $2 / 3$ \\
0.32 & 0.50 & $* * *$ & $* * *$ & int. & $2 / 3$ \\
0.67 & 0.42 & $* * *$ & $* * *$ & ext. & $2 / 3$ \\
0.18 & 0.42 & $* * *$ & $* *$ & int. & $2 / 3$ \\
0.72 & 0.28 & $* * *$ & $* * *$ & ext. & $2 / 3$
\end{tabular}

Martin et al. 
814 Table 7. Selected models for three demersal elasmobranchs, by age group (0-1 group: neonates and young; $2+$ group: sub-adult and adult; maps in

815 Figure 7) and by sex (S. canicula; maps in Figure 8), using binomial occurrence models. See Table 5 for further information.

816

817

818

819

820

821

822

823

824

825

826

827

828

829

830

831

832

833

834

\begin{tabular}{|c|c|c|}
\hline & & Model selection \\
\hline $\begin{array}{l}\text { Scientific } \\
\text { name }\end{array}$ & $\begin{array}{l}\text { Dataset } \\
\text { type }\end{array}$ & $\begin{array}{l}\text { Significant } \\
\text { predictors }\end{array}$ \\
\hline \multirow[t]{2}{*}{ R. clavata } & $0-1$ group & DEP2, STR2, SAL, 1 inter. \\
\hline & $2+$ group & DEP2, G-P-FS-M, STR, SAL2, 1 inter. \\
\hline \multirow[t]{3}{*}{ S. canicula } & $0-1$ group & DEP, M-FS-G- P, STR, SST2, SAL, 2 inter. \\
\hline & $2+$ group & DEP, P-M-G-FS, STR2, SST, SAL2, 2 inter. \\
\hline & Sex (\%Females) & DEP2, FS-M-G-P, STR2, SST, SAL2, 2 inter. \\
\hline \multirow[t]{2}{*}{ Mustelus spp. } & $0-1$ group & DEP, G-M-P-FS, STR2, SST, SAL2, 3 inter. \\
\hline & $2+$ group & DEP, M-P-G-FS, STR, SST, SAL2, 2 inter. \\
\hline
\end{tabular}

\begin{tabular}{lllllll}
\multicolumn{2}{c}{ Model evaluation } & \multicolumn{2}{c}{} \\
Adj-R & \multicolumn{2}{c}{ Spearman's } & ROC & \multicolumn{2}{c}{ Evaluation } \\
& $\mathbf{r}_{\mathbf{s}}$ & $\boldsymbol{p}$ & AUC & $\boldsymbol{p}$ & Type & Score \\
0.18 & 0.34 & $* * *$ & 0.81 & $* * *$ & int. & $3 / 3$ \\
0.13 & 0.23 & $* * *$ & 0.76 & $* * *$ & ext. & $2 / 3$ \\
0.08 & 0.30 & $* * *$ & 0.70 & $* * *$ & int. & $1 / 3$ \\
0.07 & 0.29 & $* * *$ & 0.69 & $* * *$ & ext. & $1 / 3$ \\
0.20 & 0.17 & $* * *$ & 0.85 & $* * *$ & int. & $3 / 3$ \\
0.04 & 0.10 & $*$ & 0.76 & $*$ & ext. & $1 / 3$ \\
0.24 & 0.54 & $* * *$ & 0.82 & $* * *$ & int. & $3 / 3$ \\
0.22 & 0.47 & $* * *$ & 0.78 & $* * *$ & ext. & $2 / 3$ \\
0.24 & 0.56 & $* * *$ & 0.93 & $* * *$ & int. & $3 / 3$ \\
0.23 & 0.50 & $* * *$ & 0.87 & $* * *$ & ext. & $3 / 3$ \\
0.07 & 0.26 & $* * *$ & 0.70 & $* * *$ & int. & $1 / 3$ \\
0.44 & 0.16 & $* * *$ & 0.68 & $* * *$ & ext. & $2 / 3$ \\
0.17 & 0.41 & $* * *$ & 0.79 & $* * *$ & int. & $2 / 3$ \\
0.53 & 0.31 & $* * *$ & 0.78 & $* * *$ & ext. & $2 / 3$
\end{tabular}

Martin et al. 
835 Figure 1. The eastern English Channel showing (A) geographical locations mentioned in the text, 836 and (B) trawl stations sampled during the Channel Groundfish Survey (CGFS, 1988-2008).

838 Figure 2. The spatial patterns of the environmental variables used to map the habitat models, 839 including (A) depth (m; Le Roy and Simon, 2003; Carpentier et al., 2009); (B) seabed sediment 840 type (M: mud, FS: fine sand, CS: coarse sand, G: gravel and P: pebble; Larsonneur et al., 1979); (C) 841 bed shear stress (N.m ${ }^{-2}$, Aldridge and Davies, 1993); (D) satellite-derived sea surface temperature 842 for October 1997-2008 ( $\left({ }^{\circ} \mathrm{C}\right.$; Casey et al., 2010); (E) in situ sea surface salinity (PSU; Carpentier et 843 al., 2009) for October 1997-2008.

Figure 3. Length (cm) frequency distributions of (A) Raja clavata, (B) Scyliorhinus canicula and (C) Mustelus spp., illustrating the density $\left(\log _{10}[\mathrm{x}+1]\right.$, where $\mathrm{x}=$ ind. $\left.\mathrm{km}^{-2}\right)$ of fish at length caught in the Channel Groundfish Survey. The vertical arrows indicate the estimated lengths at two years old $\left(\mathrm{L}_{2}\right)$, that were used to separate individuals into two age groups (0-1 group: neonate and young; $2+$ group: sub-adult and adult). Length at $50 \%$ maturity $\left(\mathrm{L}_{\mathrm{m}}\right)$ is shown for information $([\mathrm{F}]$ : female, $850[\mathrm{M}]$ : male). The abscises for all species start at the approximate length at birth $\left(\mathrm{L}_{\mathrm{b}}\right)$. Exact values for $851 \quad \mathrm{~L}_{\mathrm{b}}, \mathrm{L}_{2}$ and $\mathrm{L}_{\mathrm{m}}$ are listed in Table 4 .

Figure 4. Mapped binomial occurrence models (main figure) and associated prediction error (below) for (A) Dasyatis pastinaca, (B) Raja brachyura, (C) R. microocellata, (D) R. montagui, (E) R. undulata and (F) Galeorhinus galeus in the eastern English Channel during October (lengths and sexes combined). Prediction error: 0 and 1 correspond to the minimum and maximum possible errors, respectively. 
861 Channel during October (lengths and sexes combined). Delta model: showing density in

$862 \log _{10}[\mathrm{x}+1], \mathrm{x}=$ ind. $\mathrm{km}^{-2}$; prediction error: 0 and 1 correspond to the minimum and maximum 863 possible errors, respectively.

865 Figure 6. Model behaviour for each environmental variable tested, taking into account the effect of 866 each of the five seabed sediment types (see Figure 2B). Each plot illustrates the species response 867 (here density $\mathrm{x}$ ) along one given environmental gradient, all other variables remaining constant at 868 their mean value. This figure corresponds to the delta model of Scyliorhinus canicula (see map in 869 Figure $5 B)$. Units: density $\left(\log _{10}[x+1], x=\right.$ ind. $\left.\mathrm{km}^{-2}\right)$, depth $(\mathrm{m})$, bed shear stress $\left(\mathrm{N}_{\mathrm{m}} \mathrm{m}^{2}\right)$, surface 870 temperature $\left({ }^{\circ} \mathrm{C}\right)$ and surface salinity (PSU).

872 Figure 7. Mapped binomial occurrence models (main figure) for (A-B) Raja clavata, (C-D) 873 Scyliorhinus canicula and (E-F) Mustelus spp. by age group, and associated prediction error 874 (below). Prediction error: 0 and 1 correspond to the minimum and maximum possible errors, 875 respectively. The habitat model corresponding to Figure 7B did not pass the evaluation criteria.

877 Figure 8. Habitats of female and male Scyliorhinus canicula, showing (A) the proportion of females 878 based on a binomial occurrence model (and below: associated prediction error, where 0 and 1 879 correspond to the minimum and maximum possible errors, respectively). This model was used to 880 balance the delta model (see map in Figure 5B) so as to visualise spatial segregations by sex for (B) 881 females and (C) males (density in $\log _{10}[\mathrm{x}+1], \mathrm{x}=$ ind. $\mathrm{km}^{-2}$ ). 
Figures (rev2)

Figure 1.
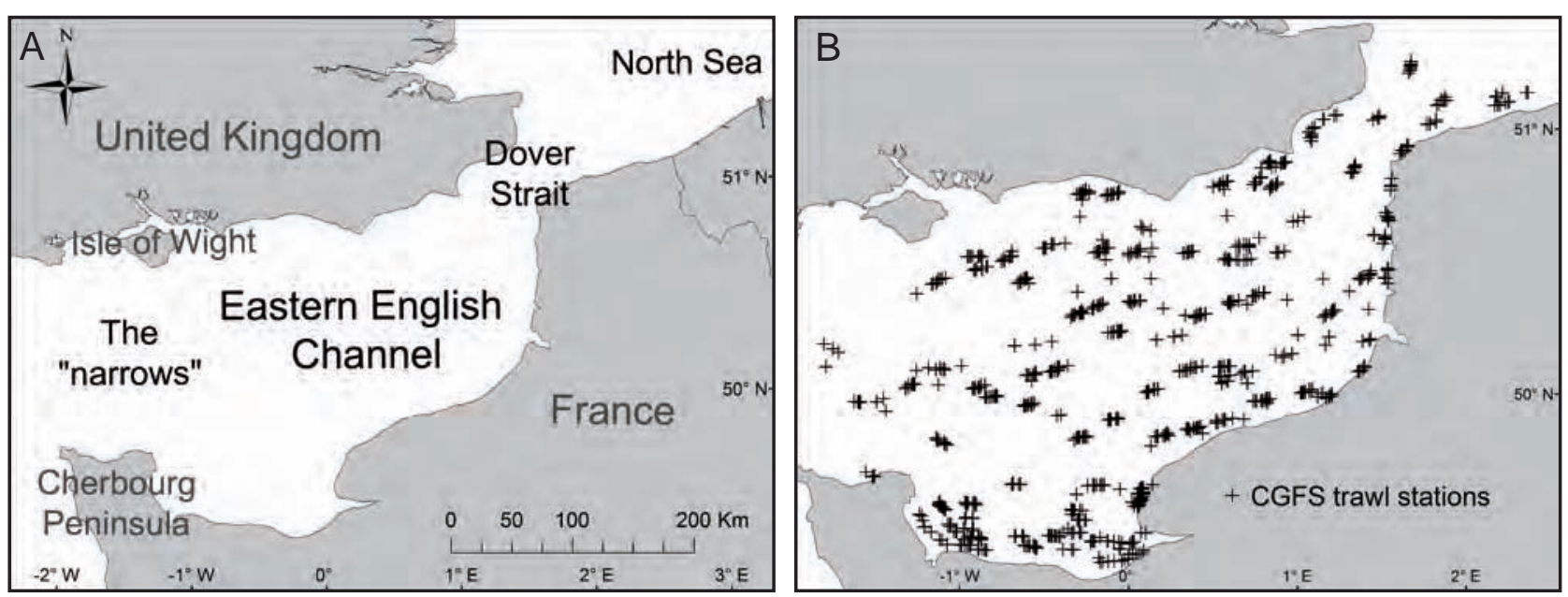

Martin et al. 
Figure 2.
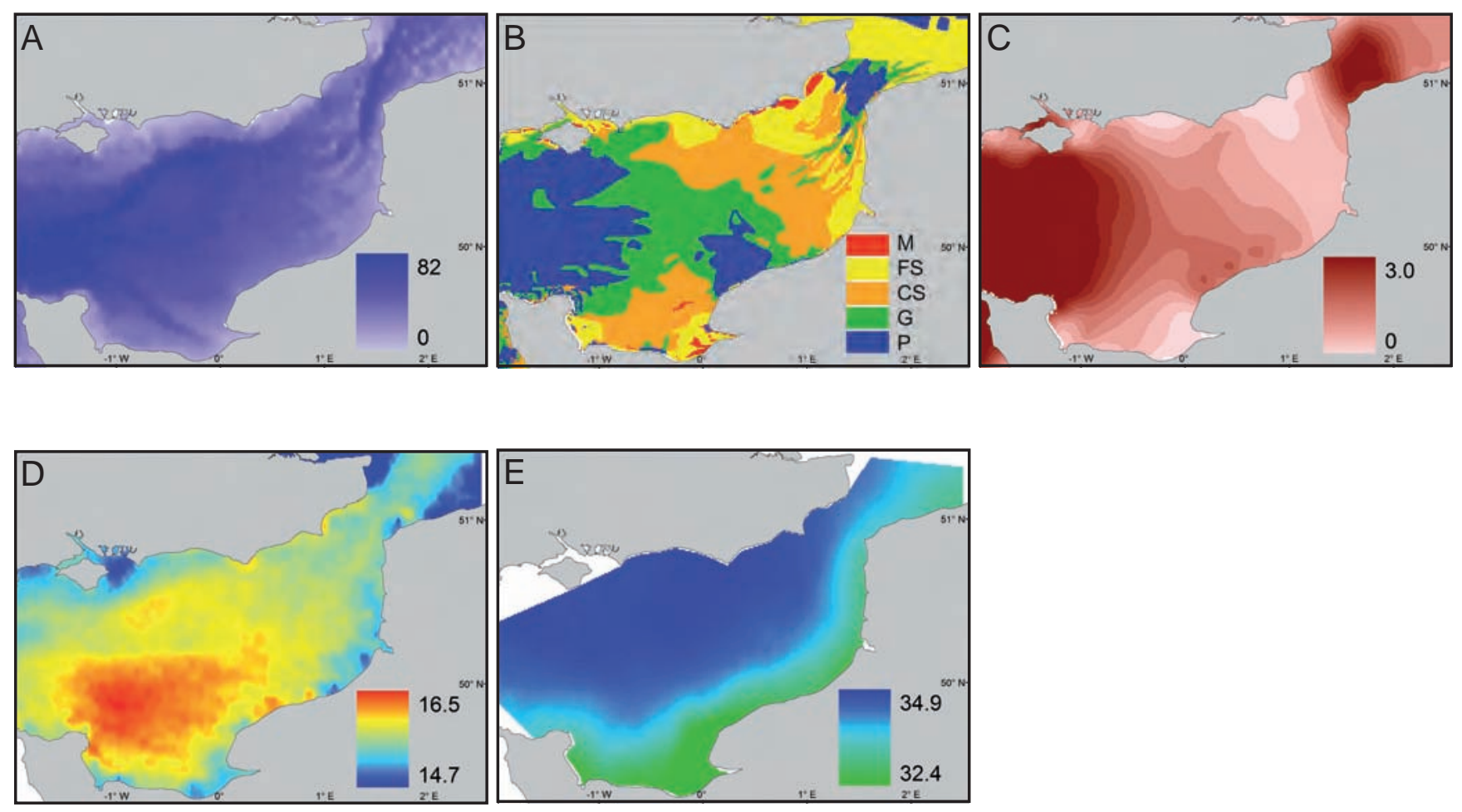

Martin et al. 
Figure 3.
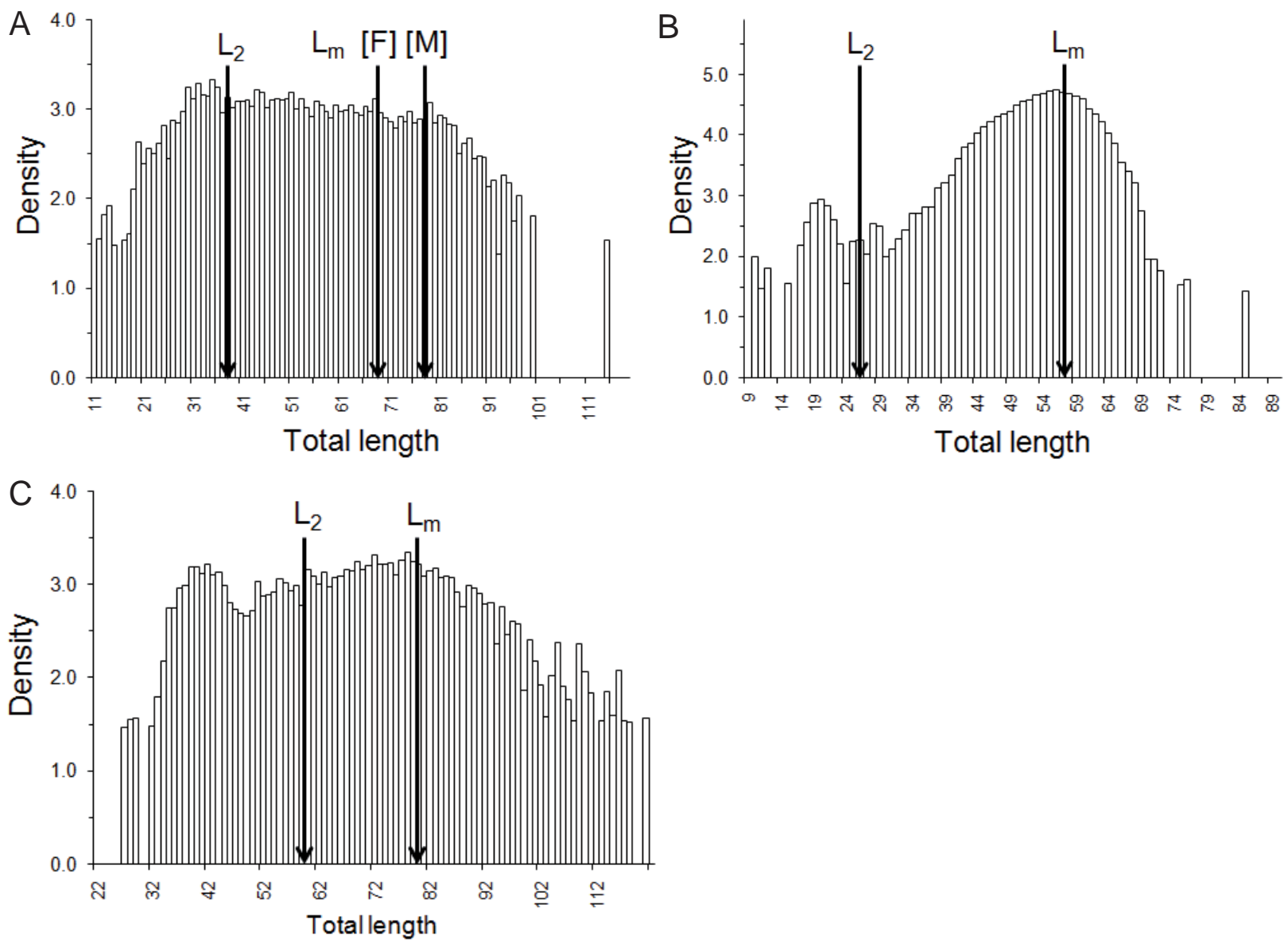
Figure 4.
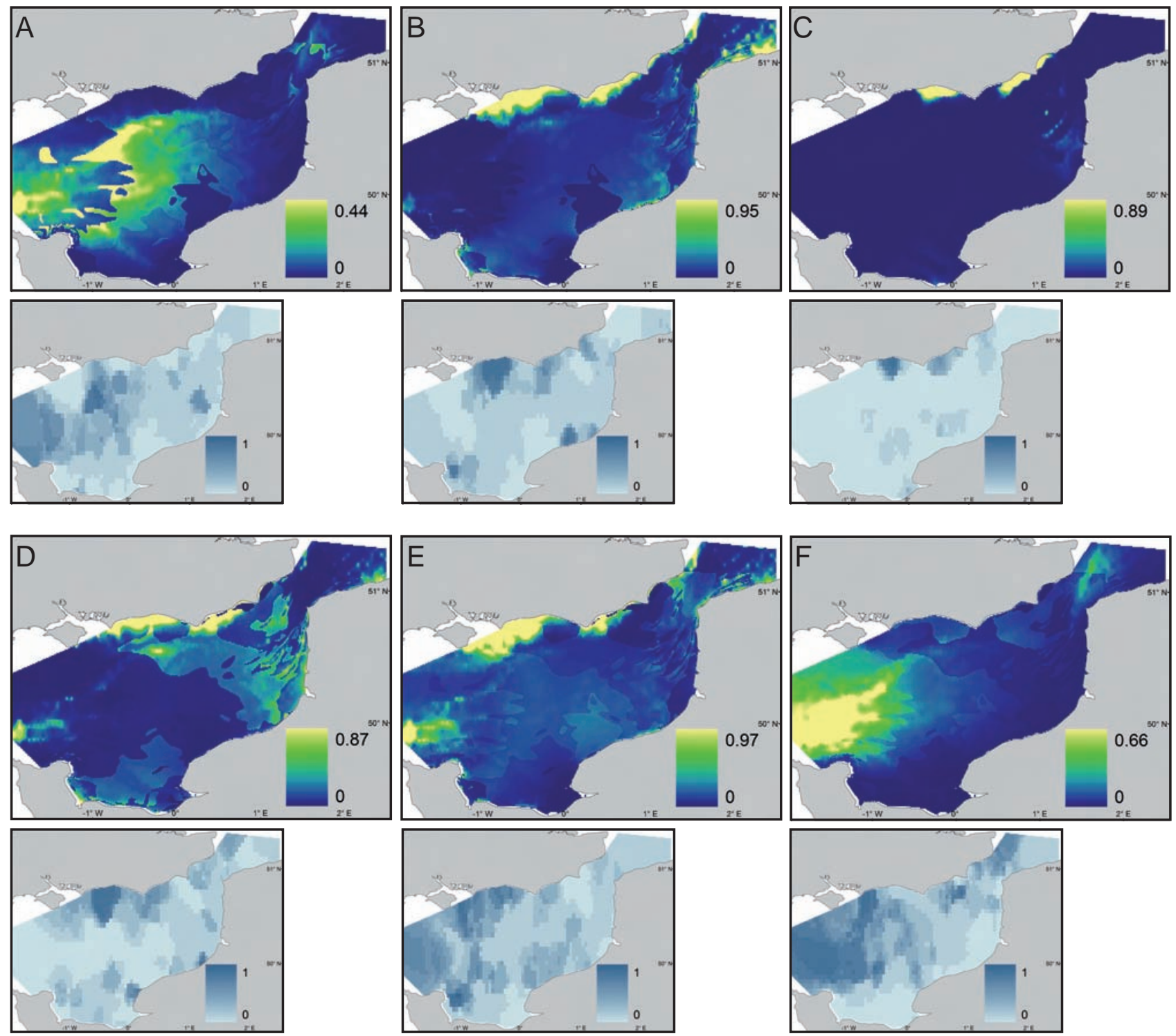

Martin et al. 
Figure 5.
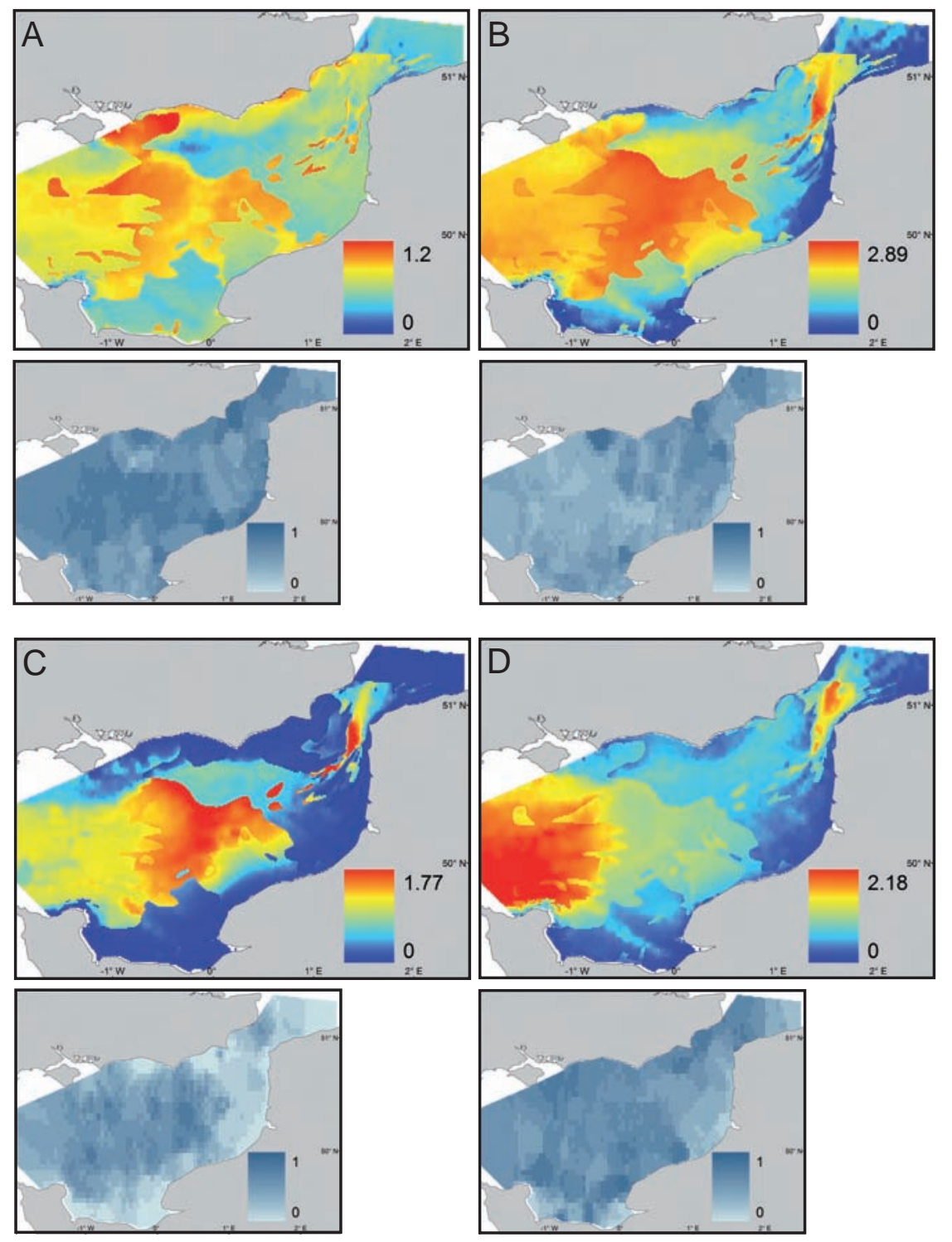

Martin et al. 
Figure 6.
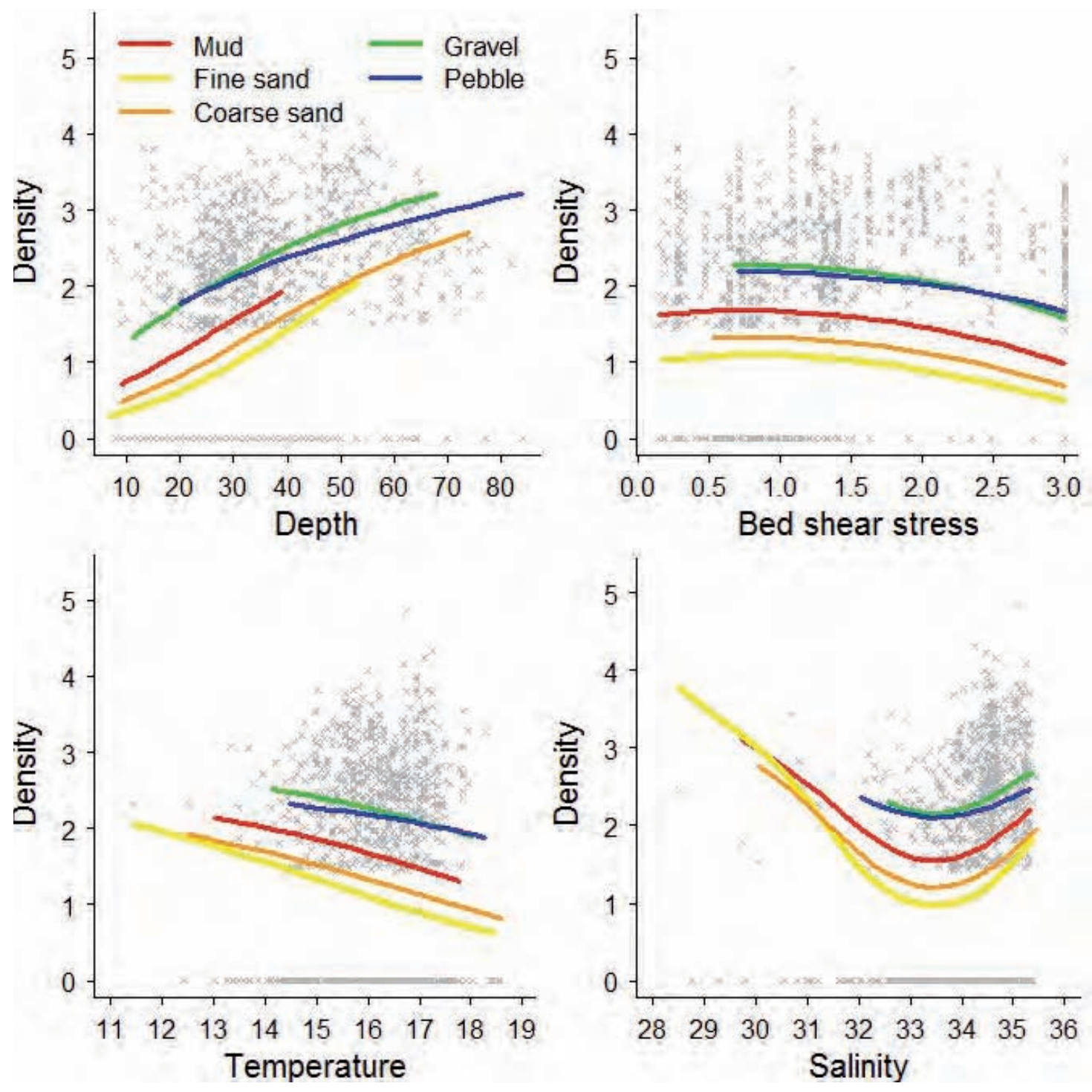

Martin et al. 
Figure 7.
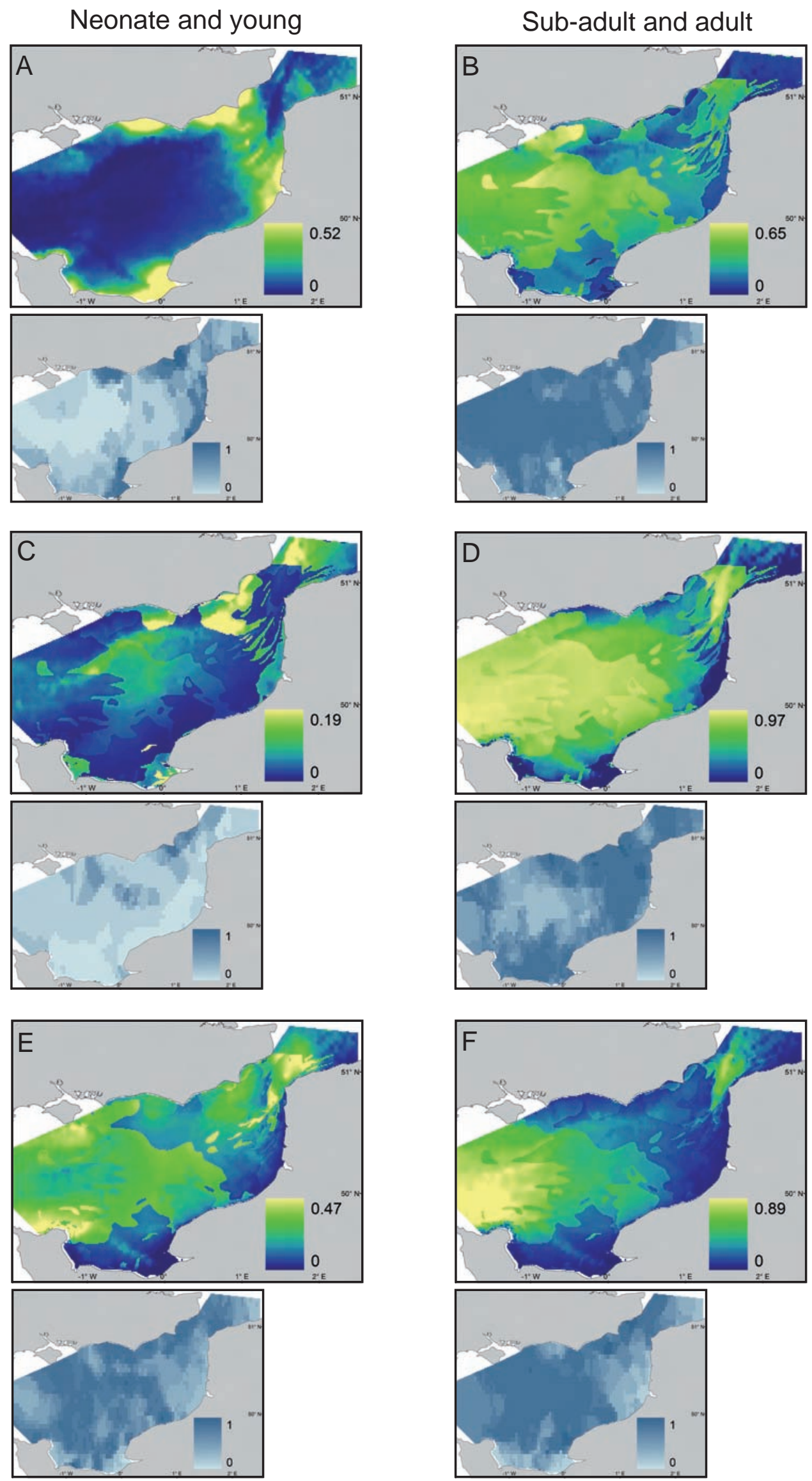
Figure 8.

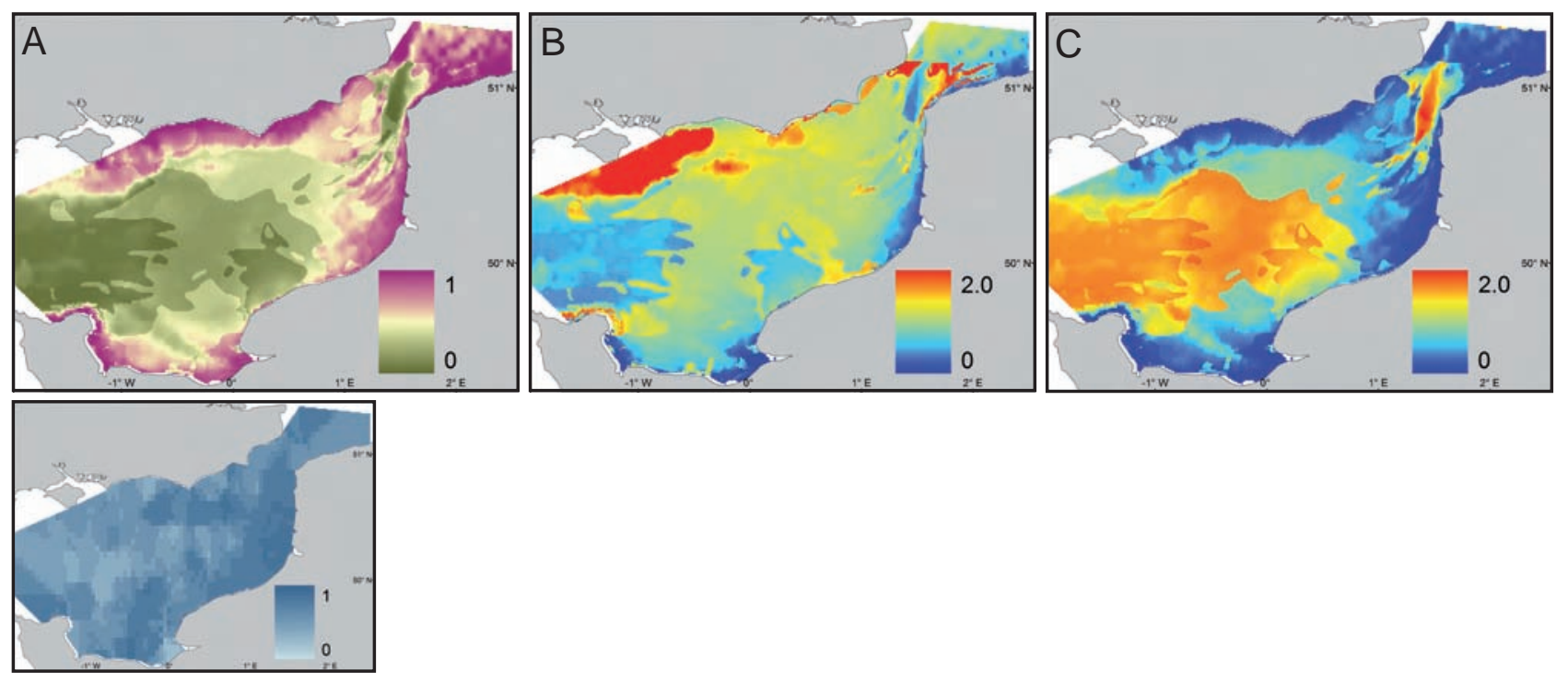

